\title{
THE STRUCTURE OF THE PROTELYTROPTERA, WITH DESCRIPTION OF A NEW GENUS FROM PERMIAN STRATA OF MORAVIA*
}

\author{
$\mathrm{By}$ \\ F. M. Carpenter, Harvard University \\ AND \\ Jarmila Kukalová, Charles University, Prague ${ }^{1}$
}

The extinct order Protelytroptera was established by Tillyard in I93I for a series of elytrophorous insects from Lower Permian deposits near Elmo, Kansas. Additional genera from the same strata were subsequently described by Carpenter (1933, 1939). Apart from one little-known species (Uralelytron martynovi Rohdendorf) from the Russian Permian and the controversial Protocoleidae from the Upper Permian of Australia, nothing more has been known of the order. $^{2}$ This meager record has given the general impression that the order was a small one, not very diversified, and unusually restricted geographically.

A very different view of the order now results from the discovery of Permian representatives in collections from Moravia (Czechoslovakia) and Australia which are being studied by one of the present authors (Kukalová); they show a diversity of wing and body structure that has not previously been expected in this order. A full treatment of the Moravian and Australian material will be published elsewhere. The present paper consists of an account of what is now known about the wing and body structure of the members of this extinct order. A description of one of the Moravian fossils is included, since it gives information about the hind wing and body of a new family; also included are the results of a restudy of some specimens from the Elmo locality, in particular types which are in the Museum of Comparative Zoology at Harvard University and the Peabody Museum at Yale University.

\section{Family Protelytridae Tillyard}

Protelytridae Tillyard, 1931, Amer. Journ. Sci. $21: 235$; Carpenter, 1933, Proc. Amer. Acad. Arts Sci. 68 :465-473.

\footnotetext{
*This research has been aided by grant no. NSF GP-2038 from the National Science Foundation.

${ }^{1}$ Current address: Biological Laboratories, Harvard University.

${ }^{2}$ The poorly known species, Arctocoleus ivensis Martynov and Bardocoleus insignis Zalessky, from Permian deposits in Russia, may also belong to the Protelytroptera.
} 
This is the only family of which the hind wing and body structure have been known. These have already been described (Carpenter, 1933) but the reconstructed figure of the whole insects, including only those details which are actually known, is included here for comparison with other families (Text-figure 2).

\section{Family Archelytridae Carpenter}

Archelytridae Carpenter, 1933, Proc. Amer. Acad. Arts Sci. 68:477.

This family is still known only by the type specimen of Archelytron superbum Carpenter, from the Elmo deposit. However, new specimens of related Protelytroptera from Moravia require a modification of our concept of this family and of the actual structure of the elytron. At the time of the description of Archelytron, no Protelytroptera were known which had cross veins on the elytra. In the original account of $A$. superbum, it was stated that cross veins were absent but that the surface of the elytron was rough and under oblique light appeared to have a series of short ridges between the veins over the entire elytron. Since the elytra of several new genera from the Permian of Moravia have numerous and distinct cross veins, we are convinced that the supposed ridges in Archelytron are also cross veins. Revised definitions of the family Archelytridae and the genus Archelytron now seem necessary.

The family Archelytridae appears to have the following characteristics: elytron only slightly convex; costal expansion weakly developed; stems of main veins independent; Sc long, well developed, terminating on costa about two-thirds wing length from the base;

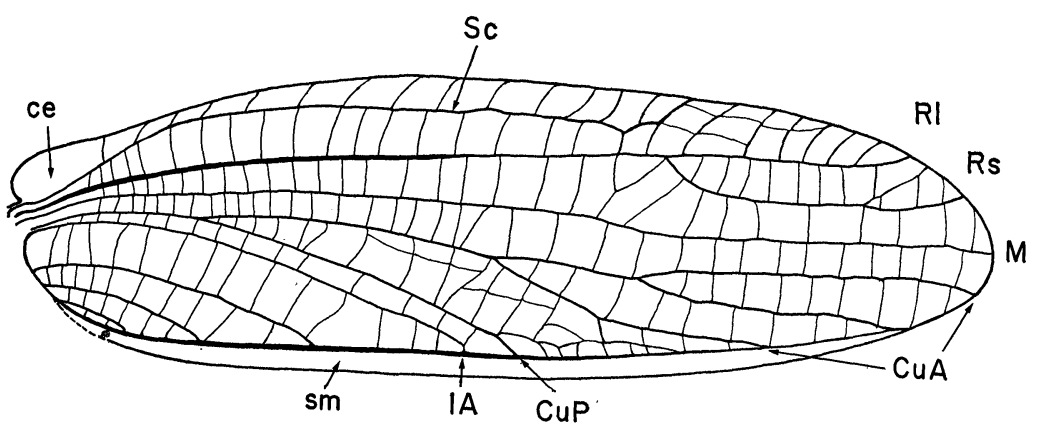

Text-figure 1. Drawing of elytron of Archelytron superbum Carpenter (holotype). Original. ce, costal expansion; Sc, subcosta; $R 1$ radius; Rs, radial sector; $\mathrm{M}$, media; $\mathrm{CuA}$, anterior cubitus; $\mathrm{CuP}$, posterior cubitus; $1 \mathrm{~A}$, first anal vein; sm, sutural margin. 
Sc, RI, CuP, IA unbranched; $\mathrm{CuA}$ usually with three branches; $\mathrm{CuP}$ markedly concave for its entire length; sutural margin well developed, its termination well before the apex; cross veins numerous but weakly developed over the entire wing; most cross veins simple, some forked or connected by transverse veinlets. Hind wing unknown.

Genus Archelytron Carpenter

Archelytron Carpenter, 1933, Proc. Amer. Acad. Arts Sci: 68:477.

Costal margin of elytron strongly convex; Sc weakly developed at the base but well formed distally; Rs originating well beyond middle of wing; $\mathrm{CuA}$ and $\mathrm{CuP}$ diverging in basal fifth of wing, $\mathrm{CuA}$ forked dichotomously near the middle of the wing, the anterior branch forking again at about the level of the origin of Rs; CuP and the anal veins sub-parallel; few cross veins connected.

Type-species: Archelytron superbum Carpenter

\section{Archelytron superbum Carpenter \\ Text-figure I}

Archelytron superbum Carpenter, 1933, ibid.: 477, fig. 22.

The specific description originally given is correct with the exception of the reference to cross veins, as noted above. In addition, it should be pointed out that the oblique vein connecting $M$ to $R s$ in the original figure of Archelytron is almost certainly a cross vein (a possibility that was mentioned in the original description) instead of part of a branch of $M$.

\section{Apachelytridae, new family}

Related to the Archelytridae. Fore wing: almost flat and thin, weakly tegminous rather than elytrophorous; costal expansion well developed and distinct; Sc prominent, probably long; main veins arising independently from the wing base; $\mathrm{CuP}$ strongly concave; $\mathrm{CuA}$ and $\mathrm{CuP}$ arising much as in Archelytridae; $\mathrm{CuA}$ with several terminal branches; sutural margin wide (length unknown); cross veins numerous and well developed over wing, mostly regular and simple.

Hind wing: anal fan large, as in Protelytridae; stem of $M$ independent of $R ; M$ forked into $M_{I}$ and $M_{2}$ near mid-wing; $M_{I}$ independent of Rs, twigged at wing apex; $M_{2}$ diverging posteriorly and coalesced with $\mathrm{CuA}$ to its termination; base of $\mathrm{Cu}$ free from the stem of $\mathrm{M}$ : IA (convex) fused with $\mathrm{CuP}$ distally; $2 \mathrm{~A}$ (con- 


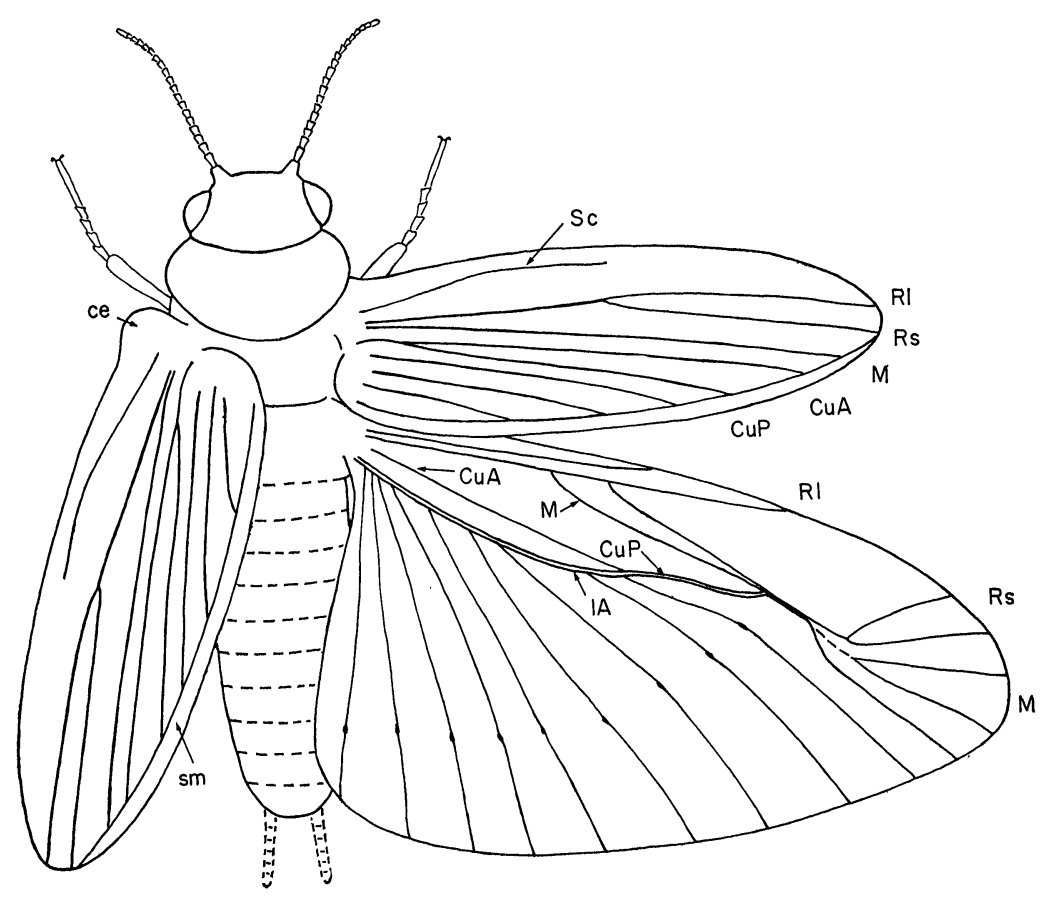

Text-figure 2. Reconstructed drawing of Protelytron perm anum Tillyard, based on specimens in the Museum of Comparative Zoology (Harvard University) and the Peabody Museum (Yale University), and showing in solid lines only those details actually preserved. The abdominal segmentation and cerci, indicated by broken lines, are unknown in Protelytron (Carpenter, 1933). Lettering as in text-figure 1.

cave) parallel with IA and somewhat close to it. IA without branches; anal veins radiating to form the anal fan; several branches arising from $2 \mathrm{~A}$; some cross veins over most of remigium, absent in anal fan.

Body structure: head with small eyes, pronotum nearly square, with posterior corners rounded, resembling a small pronotal disc; fore legs short, hind legs much longer, with well developed femora; tarsal segmentation unknown; abdomen apparently with seven normal segments, others more modified; cerci short, with distinct segmentation.

This family is differentiated from the Archelytridae by having a more distinct costal expansion and by having the cross veins of the elytra more regular and more numerous, with almost no branching. 


\section{Apachelytron, new genus}

Elytron: costal margin convex; Sc well developed, apparently extending well beyond mid-wing; Rs arising in the distal part of the wing, with several branches; $\mathrm{Cu}$ dividing into $\mathrm{CuA}$ and $\mathrm{CuP}$ remote from the wing base; $\mathrm{CuA}$ forking below origin of Rs, each division with several branches; CuP nearly straight; about 4 anal veins, all simple; cross veins well developed over all the wing, mostly straight, except in the region of Rs; no anastomosis of cross veins.

Hind wing: Rs arising well beyond mid-wing, with all its branches distal and directed towards anterior margin; $\mathrm{CuA}$ diverging before fork of $\mathrm{M} ; \mathrm{CuA}+\mathrm{M}$ with several cross veins directed posteriorly to $\mathrm{CuP}+\mathrm{IA}$; cross veins present between $\mathrm{IA}$ and $2 \mathrm{~A}$.

Type-species: Apachelytron transversum, n. sp.

\section{Apachelytron transversum, n. sp. \\ Text-figure 3 ; plate 22}

Length of right fore wing (elytron), $6 \mathrm{~mm}$; width, $2.2 \mathrm{~mm}$; length of right hind wing, $7 \mathrm{~mm}$. Since only one specimen is known and since the venation in the Protelytroptera is unusually variable (Carpenter, 1936), the specific characteristics designated are necessarily arbitrary. In this category we consider the following: Rs forked, each of the main branches dividing again at least once; $\mathrm{CuAI}$ with fewer terminal branches than $\mathrm{CuA}$. Other details are shown in text figure 2.

Type: specimen no. 47/1964, Department of Paleontology, Charles University, Prague, Czechoslovakia. Collected by A. Havlatová in Lower Permian (Autunian) clayey shale, near Obora, Boskovice Furrow, Moravia, Czechoslovakia. The type specimen is remarkably well preserved, as shown in plate I. Although the insect as a whole is seen in ventral view, there seems to be slight twisting of the abdomen. ${ }^{3}$ Not enough of the head is clear to permit an estimate of the size and shape. The pronotum is partially preserved; it appears to be about as broad as long, with the posterior angles more rounded

\footnotetext{
${ }^{3}$ This fossil shows a type of distortion not uncommon in specimens found in the clayey shale of the Obora locality; the distortion probably results from small rock movements associated with post-Paleozoic folding in the Boskovice Furrow sediments. The effect of this is to cause, in the specimen of $A$. transversum, an elongation of the wings along the longitudinal axis of the body; as can be seen in figure 2, the left hind wing is considerably longer than the right one. It is quite likely that the right fore and hind wings, which are nearly at right angles to the body, are distorted by having a somewhat greater width than in the original insect.
} 


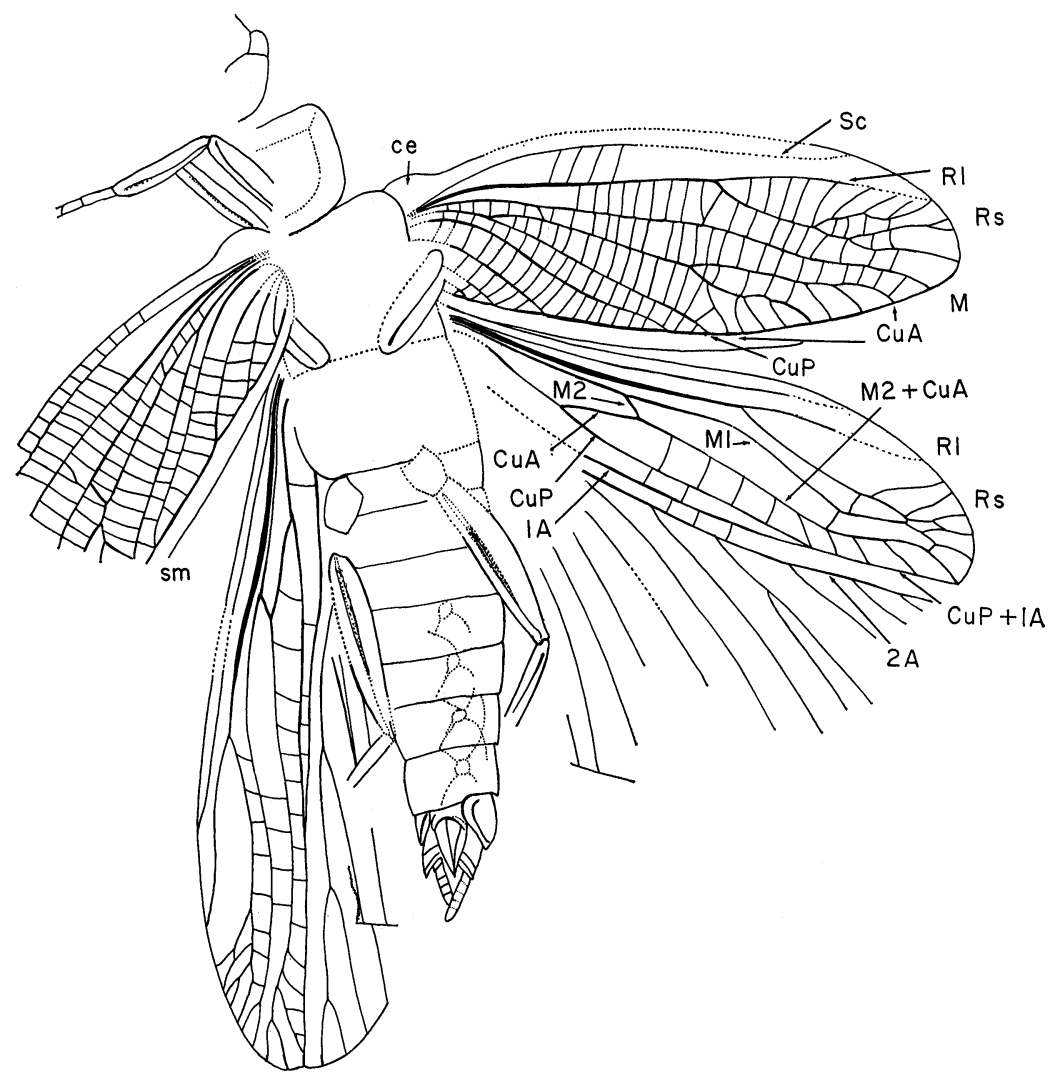

Text-figure 3. Drawing of holotype of Apachelytron transversum, n.sp. Lettering as in text-figure 1 .

than the anterior ones. The meso- and metathoracic segments are large and about square. The fore legs are short and unmodified; two tarsal segments are visible but more were undoubtedly present. The bind legs are much longer, the femur being long and quite thick. The abdomen shows seven normal segments; the remaining ones are apparently modified to form a complex of small sclerites and processes. Clearly identifiable are the two short cerci, consisting of about five segments. Two conspicuous lateral sclerites are also discernible, although these are not seen in the same position, since one is much larger than the other; they appear to be derived from the eighth segment. Between the latter plates are a pair of short, 
tapering structures, almost certainly constituting a small ovipositor.

Neither elytron is quite complete, but only two important details are missing: the point of termination of $\mathrm{Sc}$ and the distal part of the sutural margin. In all probability both of these were as described for Archelytron. In both elytra one cross vein between $\mathrm{M}$ and $\mathrm{CuA}$ is slightly oblique, but this is not heavier than the others and seems almost certainly not a branch of $M$.

The hind wing seems only slightly longer than the fore wing; the subcosta is distinctly longer than in Protelytron; Rs arises after the mid-wing, much later than in Protelytron; the stem of $\mathrm{M}$, although not fused with $\mathrm{R}$, as in Protelytron, is very close to it, especially proximally. The anastomosis of $\mathrm{CuA}$ and $\mathbf{M}$ is very different from the structure of these veins in Protelytron and the fulcrum of the latter is completely absent, although it is suggested by the convergence of $\mathrm{Rs}, \mathrm{M}$ and $\mathrm{CuA}$ distally. Another striking difference between Protelytron and Apachelytron is in the configuration of $\mathrm{CuP}, \mathrm{IA}$ and $2 \mathrm{~A}$. In Protelytron $\mathrm{CuP}$ and $\mathrm{IA}$ are very close together and parallel and IA gives off a long series of radiating anal veins. In Apachelytron $\mathrm{CuP}$ and $\mathrm{IA}$ are remote proximally, though fused distally; and $2 \mathrm{~A}$ gives rise to the radiating anal veins. ${ }^{4}$ It is apparent that more differences exist between the hind wings of Protelytron and Apachelytron than between the elytra.

\section{Family Blattelytridae Tillyard}

Blattelytridae Tillyard, 1931, Amer. Journ. Sci. $21: 249$; Carpenter, 1939, Proc. Amer. Acad. Arts Sci., 73:60.

This family, which now includes several species of Parablattelytron, one of Permelytron (probably inseparable from Parablattelytron) and the type-species of Blattelytron, has been known up to the present time only by elytra. The venation of the elytra shows much individual variation in the degree of development of the veins (Carpenter, 1939, p. 62); the family is characterized so far as the elytra are concerned by the obsolescent nature of the veins of the elytra and probably also by the absence of Rs. One specimen of Parablattelytron subincisum Tillyard, collected at the Elmo locality in 1958 , is nearly complete, showing the hind wings as well as parts of the body and the elytra. Since this has not previously been described, it is considered here in order to permit comparison with the complete specimens of Protelytron and Apachelytron.

\footnotetext{
${ }^{4} \mathrm{~A}$ somewhat similar variation in the origin of the anal veins forming the fan of the hind wing occurs in the Blattaria.
} 


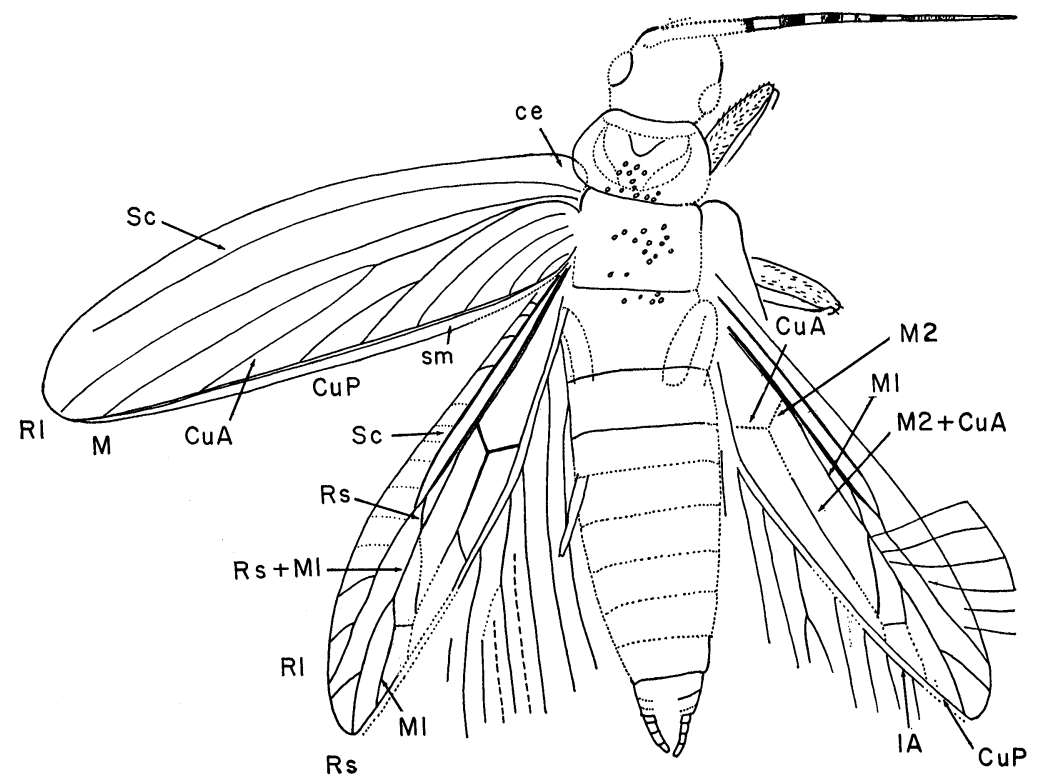

Text-figure 4. Drawing of Parabattelytron subincisum Tillyard, based on specimen no. 5827, Mus. Comp. Zool. Lettering as in text-figure 1.

The venation of the elytron of this specimen (text-figure 4) is typical of that of well preserved specimens of Parablattelytron: the veins are about as long as in the Protelytridae but are very faint and fade out in their distal portions. The remigia of both hind wings are preserved but the anal fans are represented only by the more basal parts of the radiating anal veins. The subcosta of the hind wing terminates on $\mathrm{R}_{\mathrm{I}}$, instead of on the costal margin as in the hind wings of Protelytron and Apachelytron. RI continues for a considerable distance beyond the end of Sc, finally terminating on the costal margin not far from the probable apex of the hind wing; weakly developed but distinct cross veins are present in the costal area along the length of $\mathrm{Sc}$ as well as along $\mathrm{R}_{\mathrm{I}}$ beyond the end of $\mathrm{Sc}$; Rs arises from $\mathrm{R}$ just before the termination of $\mathrm{Sc}$ and anastomoses for a short distance with $M$; thees two veins separate before terminating at the apex of the wing; $M$ arises from the base of the wing as an indepedent vein and continues very close to $R$ until near mid-wing (as in Apachelytron), when it forks into $\mathrm{M}_{\mathrm{I}}$ and $\mathrm{M}_{2}$; MI continues in a nearly straight line, diverging only slightly from 


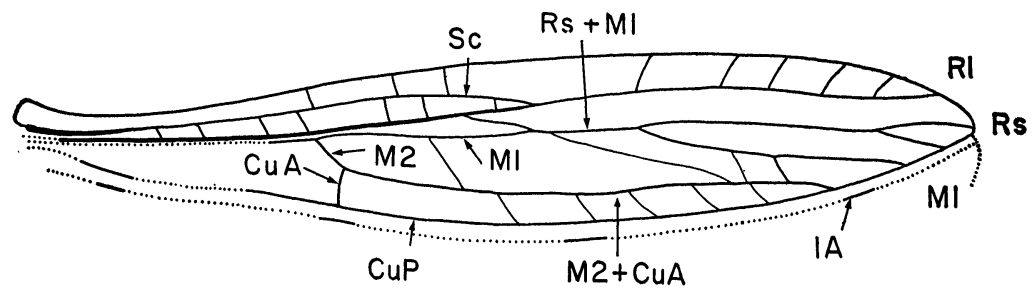

Text-figure 5. Drawing of specimen (hind wing) of Blattelytridae from Obora, Moravia (Lower Permian), no. 6/1965, Department of Palaeontology, Charles University, Prague. Lettering as in text-figure 1.

$\mathrm{R}$, then anastomosing with Rs; $\mathrm{M} 2$ diverges posteriorly abruptly after its origin and anastomoses with $\mathrm{CuA}$, which is directed anteriorly away from the stem of $\mathrm{Cu}$; these two veins, together with their fused portions, form a very distinct "Y" vein, which terminates on $\mathrm{CuP}$ well before the apex; $\mathrm{Cu}$ arising as an independent vein from the base; IA also arising from the base, close to $\mathrm{CuP}$, and continuing parallel to it and very close to it for its entire length to the apex of the wing; a series of radiating anal veins extends from IA, forming the anal fan. As shown in text-figure 3, the remigia of the right and left sides are slightly different in shape; the hind wing on the right probably has more distortion than that on the left, as indicated by the presence of some of the anal veins across the tip of the remigium.

The body structure of this specimen of Parablattelytron is only moderately well preserved; the abdomen is suggested by an outline in the matrix, although the terminal segments, with a pair of cerci (length, I.2 mm.), are distinct; the distance from the point of attachment of the elytra to the end of the abdomen is about the length of the elytra, indicating that the abdomen as a whole was covered by the elytra when they were folded back over the body. The pronotum is much broader than long, with a slightly concave anterior margin. The thoracic nota are irregularly rough in appearance and seem to bear short, truncate tubercles. Only the femora of the front and middle legs are preserved, these bearing short setae. The head is only vaguely indicated but it is distinctly smaller and narrower than in Protelytron and Apachelytron. One antenna, clearly preserved, is $4 \mathrm{~mm}$. long, relatively broad at the base but tapering abruptly; about I7 segments are visible but there were probably 


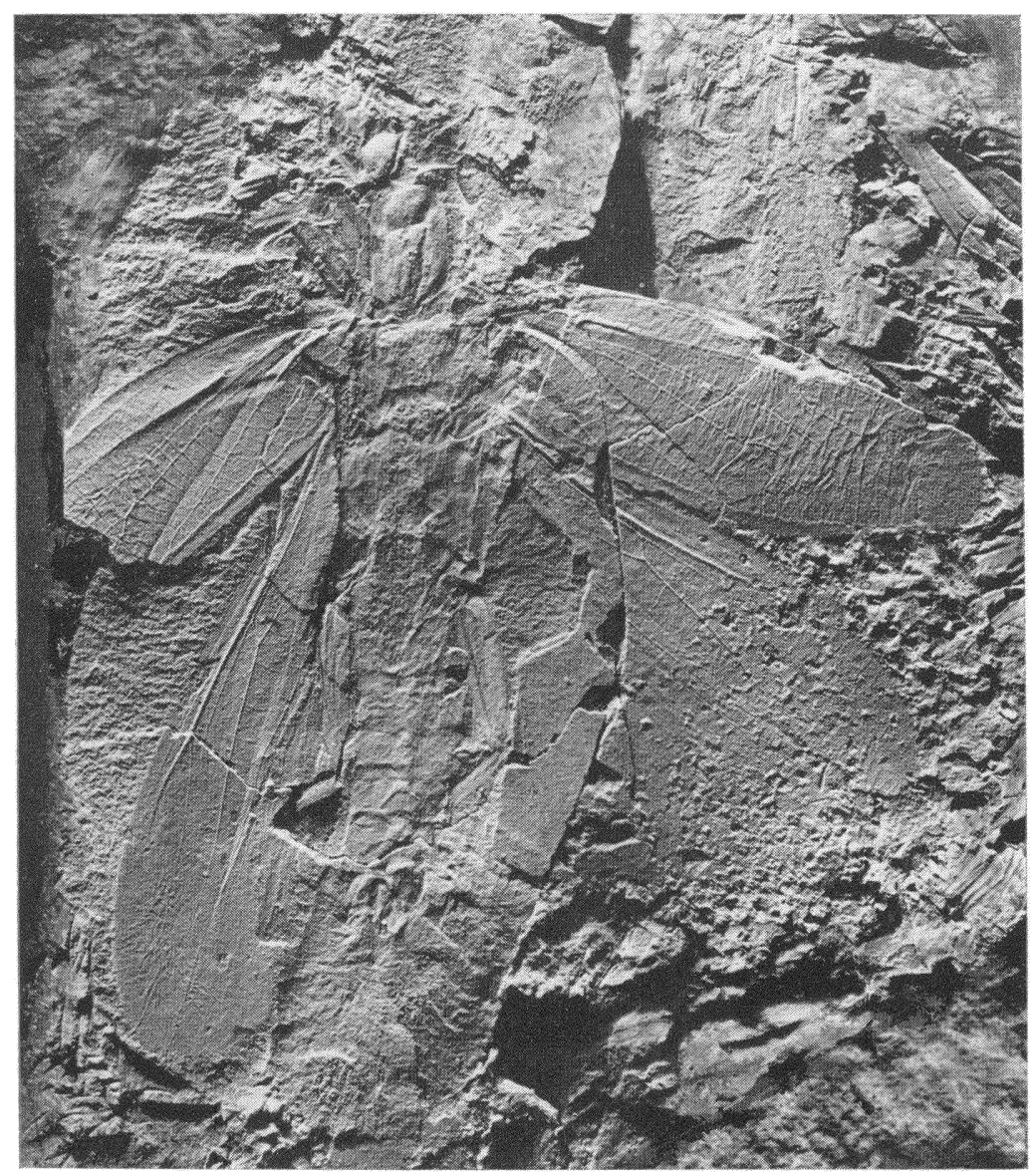

Photograph of holotype of Apachelytron transversum. n.sp. Original. $\times 7.5$. 
several more in the basal part, which is not preserved. The proximal segments show distinct signs of alternation of color.

The family Blattelytridae is apparently represented in the Lower Permian deposit in Moravia. One specimen from this locality consists of a remigium of a hind wing (text-figure 5), the venation of which is so nearly like that of Parablattelytron that we consider its family assignment almost certain. $U p$ to the present, however, no elytra have been found in the Moravian deposit which can be associated with this hind wing.

\section{Family Megelytridae Carpenter}

Megelytridae Carpenter, 1933, Proc. Amer. Acad. Arts Sci. 68 :476

This family is still known only by the type specimen of Megelytron robustum Tillyard, from the Elmo locality. Examination of this fossil (Peabody Museum, Yale University) in the light of the additional and related Protelytroptera now at hand, convinces us that the sutural margin is present and that the venational pattern is quite different from its representation in Tillyard's figure. The fossil is actually very poorly preserved and the venational details can be ascertained only with great difficulty. The family may now be characterized as follows: elytron thin, only slightly convex; costal expansion not developed as a distinct lobe; costal area uniformly broad; $\mathrm{R}$ very strong; Rs arising in distal part of wing, branched; $\mathrm{M}$ and $\mathrm{CuA}$ apparently unbranched; $\mathrm{CuA}$ and $\mathrm{M}$ coalesced basally, separating just before mid-wing; several indistinct, oblique veinlets in the costal area and weak, widely spaced cross veins in other regions of the wing; elytron with a dense cover of fine hairs. The hind wing is unknown.

\section{Megelytron robustum Tillyard}

Text-figure 6

Megelytron robustum Tillyard, 1931, Amer. Journ. Sci. $21: 247$.

A drawing of the type specimen is given in text-figure 6 . The fossil consists of the two elytra folded back over the body; the pronotum and two of the fore legs are preserved. This is the only specimen so far described which shows the position of the elytra at rest. As indicated in the drawing, the sutural margins of the elytra overlap. The venation is very poorly preserved and both Tillyard (I93I) and Carpenter (I933) were misled by the appearance of a coarse reticulated network in the distal part of the elytron, as well as by the apparent existence of weak veins in the anal region. Re- 


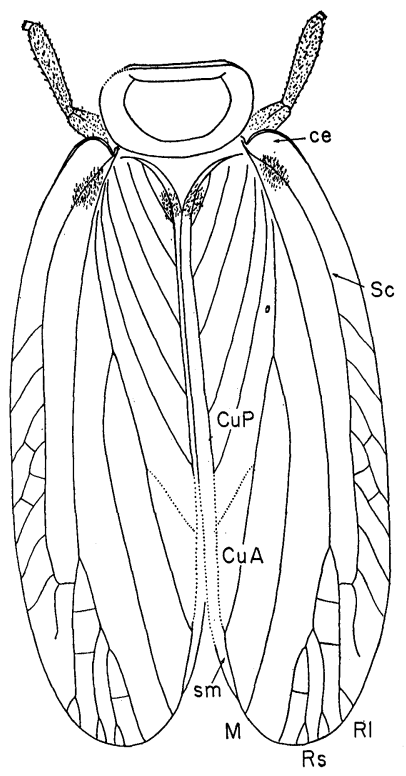

Text-figure 6. Drawing of holotype of Megelytron robustum Tillyard (holotype). Original. Lettering as in text-figure 1.

examination of this fossil has convinced us that the supposed reticulation and some weak veins in the elytron are only impressions of parts of the hind wing venation. The vein which Tillyard identified as $M$ in his figure is clearly a hind wing vein; this is also true of the peculiar veins which he shows in the anal region of the elytron. Use of ammonium chloride covering on the fossil has indicated the difference between the veins which are actually part of the elytron and those which show through from the hind wing below. The venation of the elytron, as it now seems with reasonable certainty, is shown in the accompanying figure (text-figure 5).

In addition to having the small clusters of setae in the region of the base of the subcosta and the inner angle of the anal area, the elytra of Megelytron are covered with fine hairs; no other elytra of Protelytroptera which have been described have shown hairs so distinctly and so dense, although a punctation or some other type of sculpturing is usual. The type specimen of Megelytron also shows a pronotal disc which resembles that in Parablattelytron. The leg segments, apparently the femora and tibiae, are not distinctive except 
for the presence of a fine hair covering and several rows of coarse setae.

\section{General Characteristics of the Order Protelytroptera}

The present indications are that the order Protelytroptera was a large and varied group of insects during the Permian times. The general characteristics which have been applied to this order (Carpenter, 1933) now require considerable modification as a result of even the relatively few additional species which have been studied in the past few years. The following account summarizes these characteristics as we now know them.

In what are almost certainly the more primitive forms, the fore wings are tegminous or almost flat, the costal expansion only slightly enlarged and the sutural margin either completely missing (Elytroneuridae) or at most not fully developed (Archelytridae). The thinner types of fore wings often have cross veins (Archelytridae, Apachelytridae), eventually with the addition of diverse kinds of sculpture (Protocoleidae). In others, presumably more highly specialized species (e.g., Protelytridae and Blattelytridae), the fore wings are convex and strongly sclerotized, forming true elytra. The sculpturing in these is in the form of either an indistinct rugosity or conspicuous reticulation, often arranged in complicated patterns. The veins of such elytra have few branches and are always indistinct, even to the degree of being obsolescent (Carpenter, I933). The hind wing is known in three families, the Protelytridae, Blattelytridae and Apachelytridae. In all of these a well developed anal fan is present, this being made up of radiating anal veins. The remigium is distinctly narrow. Differences in the venational patterns of the remigium of these three families are very striking. In the Protelytridae, Rs, $\mathrm{M}$ and apparently $\mathrm{Cu}$ and $\mathrm{IA}$ coalesce to form a strongly sclerotized plate, which Tillyard has designated the fulcrum and which he considered comparable to a similar structure in the Dermaptera. This was, in Tillyard's opinion, developed in connection with the evolution of the folding of the hind wings. The reduction of the main veins in the hind wing is undoubtedly a specialization relating to wing folding. In the other two families, the hind wing is much less modified; neither one has a fulcrum, although in the Apachelytridae the distal parts of the veins are in close association in the general region where the fulcrum in the Protelytridae occurs. In the Blattelytridae, on the other hand, the hind wing does not show even this trend. It is surprising that in the Blattelytridae, which have the more highly specialized elytra, the 
hind wings are much less specialized than those of the Protelytridae. There seems to be little question on the basis of the evidence which Tillyard has given (193I) that the remigium of the protelytrid hind wing was capable of transverse folding at the level of the fulcrum; the hind wing is distinctly longer than the fore wing and the presence of the "hinges" on the anal veins, in line with the fulcrum, is indeed strong evidence. On the other hand, it is doubtful that the hind wings of the Blattelytridae were capable of transverse folding; indeed, the hind wings, as they are known to us in this family, are not as long as the front wings and could, therefore, have been completely covered by the elytra in the resting position without the transverse folding. In the case of the family Apachelytridae, the hind wing is slightly longer than the elytra but there are no signs of "hinges" on the veins and the fulcrum is not developed. The condition of the wings and wing venation strongly indicates that these three families are not part of a single evolutionary line within the order but represent three radiating lines. It is especially interesting to note in the Apachelytridae $\mathrm{CuP}$ and IA are not close together or parallel, as they are in the other two families.

The body structure of the Protelytroptera is not sufficiently known to permit any general conclusions about lines of evolution within the order. The head apparently was relatively small with prominent eyes. The antennae prominent, relatively thick basally; known only in the Protelytridae and the Blattelytridae, they are about half the length of the fore wing. The prothorax apparently included a small pronotal disc. The prothoracic legs were apparently short, with five tarsal segments; the hind legs were much longer apparently with well developed femora and five tarsal segments, also. The abdomen terminated in a pair of short but distinctly segmented cerci; the females (Apachelytridae) apparently possessed a short ovipositor.

\section{REFERENCES}

Carpenter, F. M.

1933. The Lower Permian Insects of Kansas. Part 6. Proc. Amer. Acad. Arts Sci. $68: 411-503$.

1939. The Lower Permian Insects of Kansas. Part 8. Proc. Amer. Acad. Arts Sci. $73: 29-70$.

Martynov, A. V.

1932. Permian Fossil Insects from the Arkhangelsk District. Part II. Trav. Inst. Paleozool. Acad. Sci. URSS. 2:63-96.

ROHDENDORF, B. B.

1939. A new Protelytropteron from the Permian of the Urals. C. R. Acad. Sci. URSS. $23: 506-508$. 
Tillyard, R. J.

1931. Kansas Permian Insects. Part 13. The new order Protelytroptera. Amer. Journ. Sci. 21 :232-266.

ZALESSKY, G.

1947. Regarding two new Permian beetles. Doklady Akad. Nauk. $56: 857-860$. 

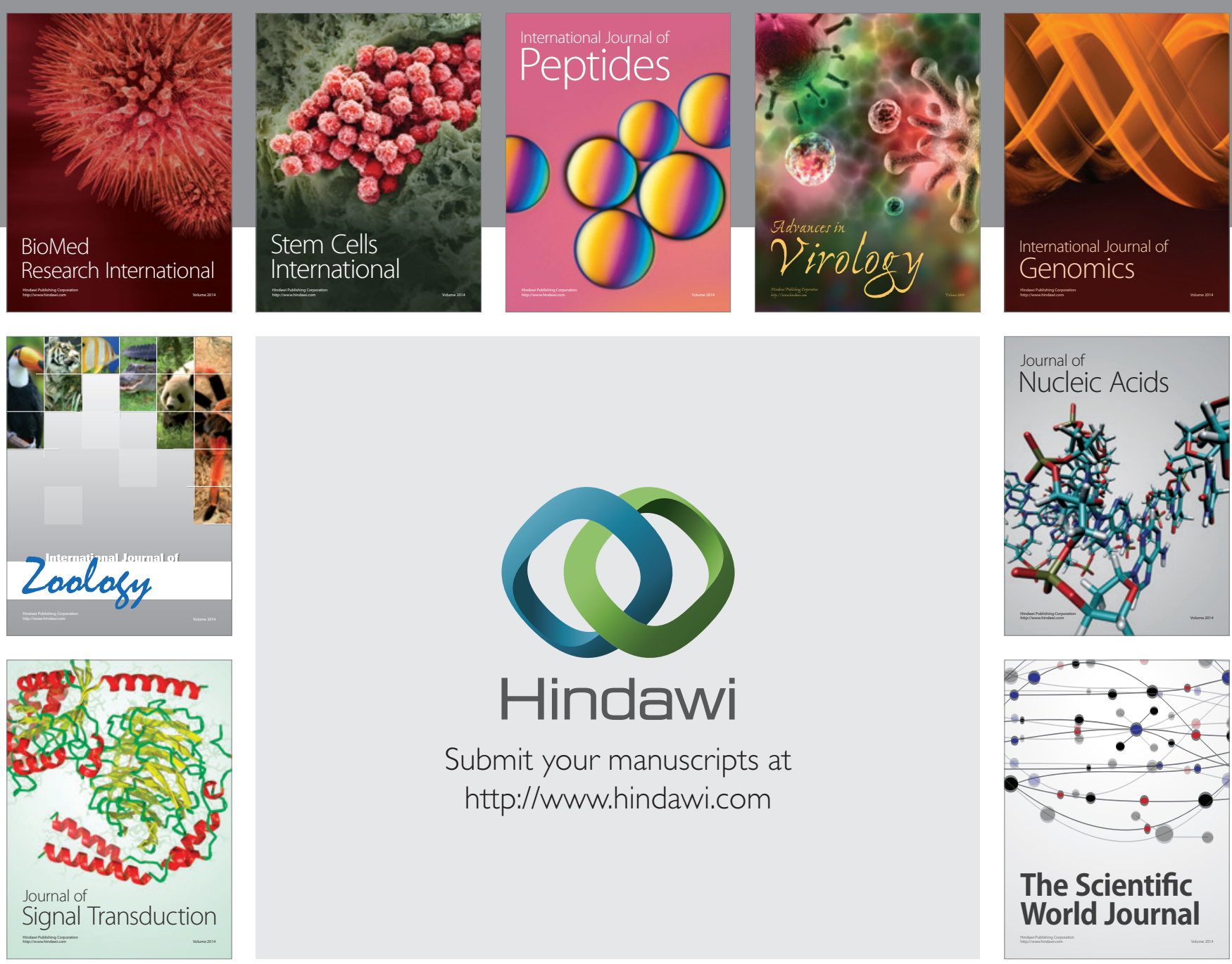

Submit your manuscripts at

http://www.hindawi.com
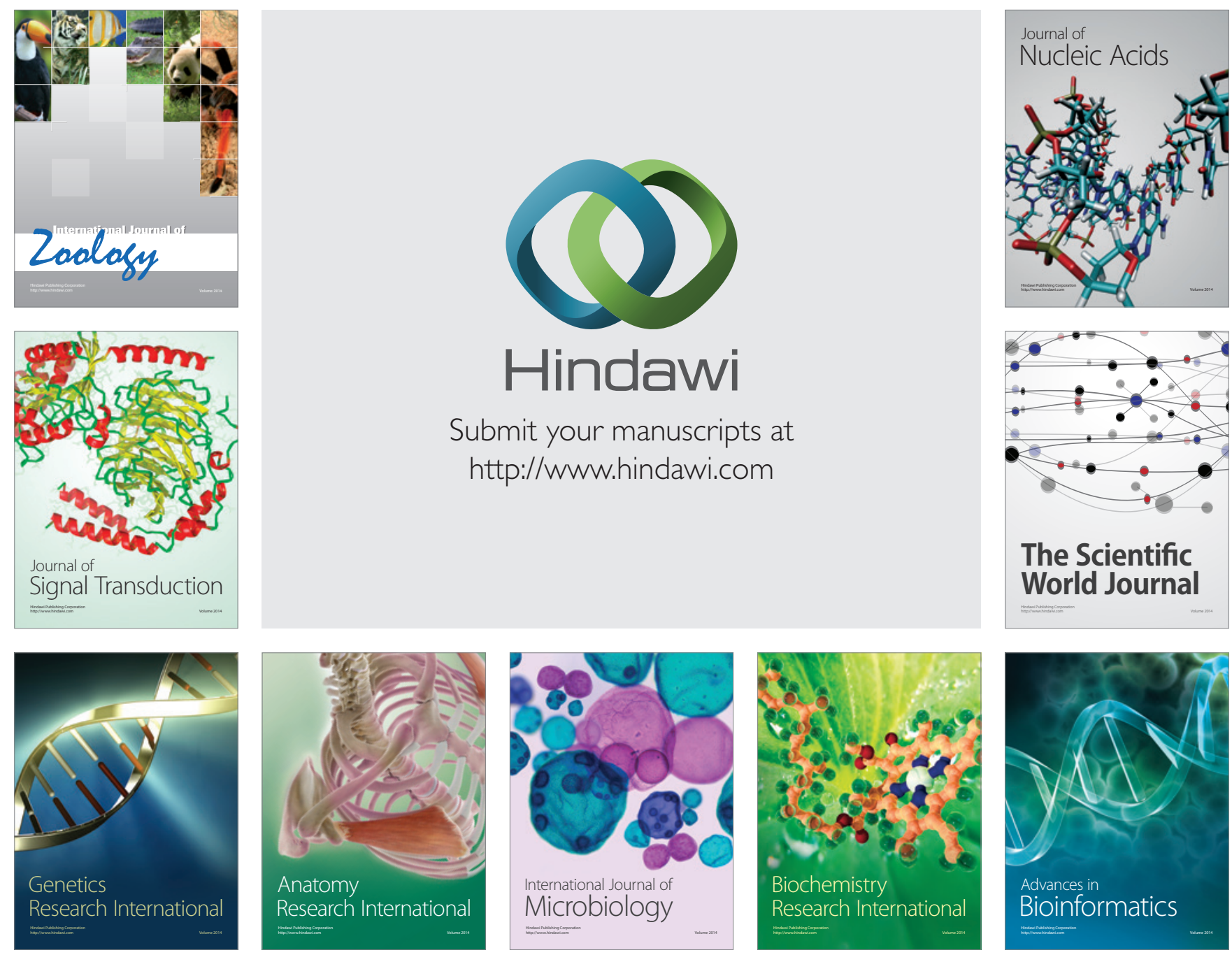

The Scientific World Journal
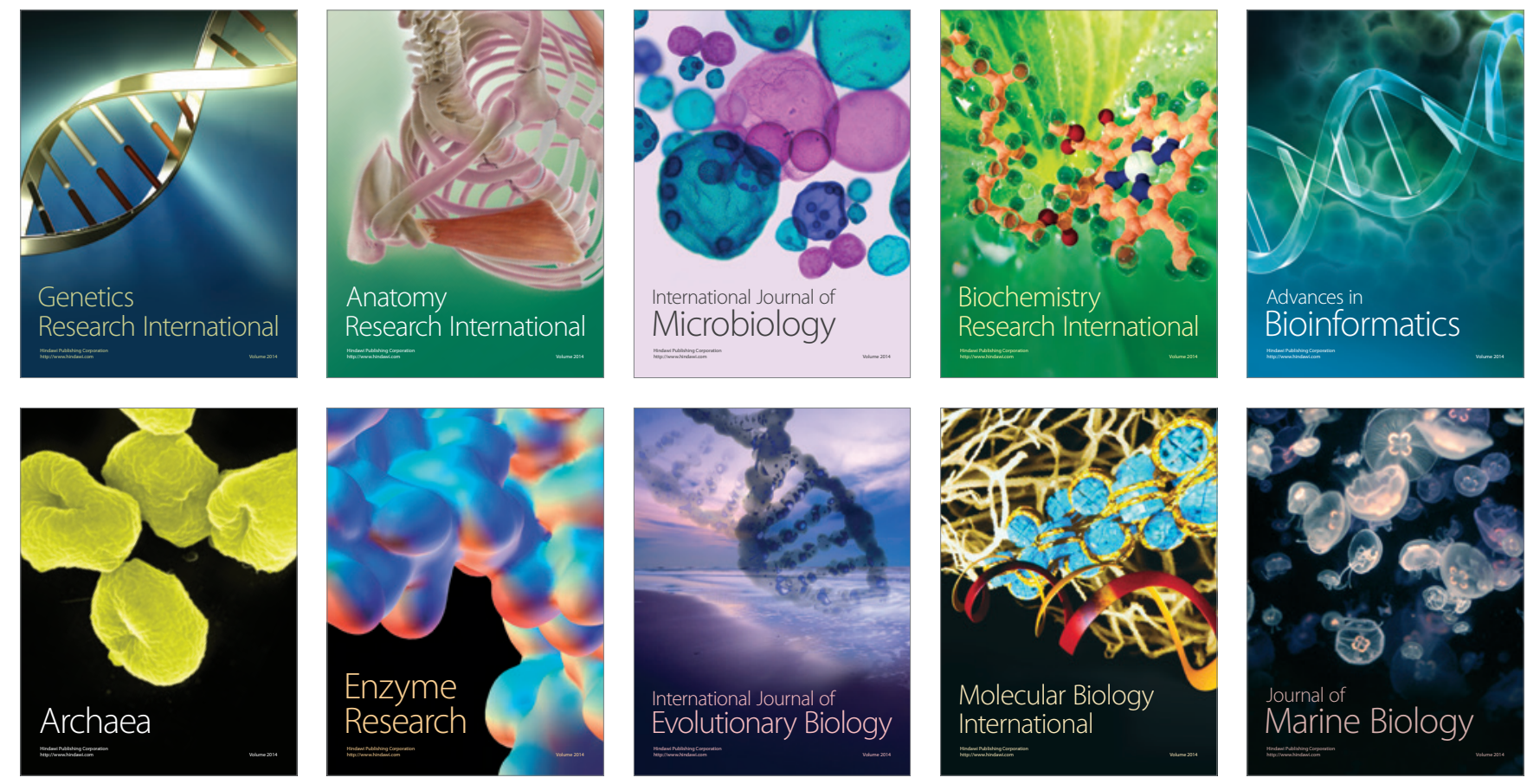